\title{
Evaluating Post Merger Pakistan Stock Exchanges' Market Efficiency
}

\author{
MUHAMMAD AMIN KHAN \\ MBA Student, Institute of Business Studies and Leadership \\ Abdul Wali Khan University, Mardan \\ IHTESHAM KHAN \\ PhD Scholar-Institute of Business Studies and Leadership \\ Abdul Wali Khan University, Mardan \\ Ihtishamkhan@awkum.edu.pk \\ DR. ADNAN AHMAD \\ Assistant Professor, Institute of Business Studies and Leadership \\ Abdul Wali Khan University, Mardan \\ adnankhattak@awkum.edu.pk
}

\begin{abstract}
The development and the formation of financial markets and institutions is indeed very instrumental for causing the robust economic growth. Although, as a fact the security prices are readily fluctuated by the market information known as market efficiency, making it a riskier investment. Subsequently, the investors accept the undiversifiable risk (Systematic risk) and cancel out the diversifiable risk (Unsystematic risk) through active diversified Portfolio Management, such a portfolio of securities, selected through market information reflects market efficiency. Thus, this study investigates the post- merger market efficiency for the Pakistan stock exchange as the three stock exchanges of the country has recently merged into Pakistan stock exchange. The analysis is based on event methodology, covering the pre-post-merger accumulated daily abnormal returns for a duration of 90 days (three months). Thus, the study proofs with respect to the accumulated daily abnormal returns, that the merger has increased the market efficiency. Consequently, the study supports the extant literature on merger and related market efficiency and provides another empirical evidence with respect to a developing country such as Pakistan. Rationally, the recent increase in the market efficiency will assure the supply of correct market information; consequently, boosting confidence of all investors and the regulators have a great opportunity to pursue continuous improvement in the present regulatory polices to promote healthy investment environment and increase the national revenue as well.
\end{abstract}

Keywords: Merger and acquisition, market efficiency, event methodology, accumulated abnormal returns.

\section{Introduction}

The establishment and flourishment of the Financial Markets and Institutions is very crucial for real economic prosperity. Among the Financial Markets, the Secondary markets are important and large markets. These secondary markets are also called Stock exchanges, where securities are exchanged for a market price. 
Karachi stock exchange was the first security exchange in Pakistan, incorporated on 10 March 1949 in Karachi. After a span of few decades, three stock exchanges were functional in Pakistan by 1992. Although, initially in all stock exchanges old methods of trading were used until 2000, when the CTS (Computerized Trading System) was introduced replacing the "Out Cry Method". Gradually, the stock exchanges were modernized through computerized trading and the recent facility of instant trading through internet is increasing the stock exchanges' efficiency and effectiveness. Furthermore, on 11 Jan 2016, the Government of Pakistan had issued an award, ordering the merging of the three stock exchanges into a single security exchange market, recognized as Pakistan Stock Exchange (PSX). Obviously, the current change has increased the securities' liquidity and as now the administration is focusing on one market containing the three former stock exchanges, so any decision of development, modernization etc., will affect all of them equally and uniformly (PSX, 2017).

Investors have a common desire to increase their wealth, therefore, they invest their savings in securities. One of the main aim of the firm management is to maximize return by minimizing risk and ultimately increasing shareholders' wealth.Mergers tend to increase the availability of firms' information to all these stakeholders to make informed decisions. Market efficiency is the timely availability of requisite information to all the stakeholders simultaneously and its rapid reflection in the stock prices (Fama,1970). On the other hand, if a specific individual or party had access to the information and use it for generating significant return, then the market is inefficient (Dimson\&Mussavian,1998). Furthermore, high and reliable availability of market statistics leads to increased market efficacy.Fama (1970) had reported that there three categories of market efficiency known as, Weak form tests, Semi-Strong form tests and Strong form tests.

Based on the above theory of market efficiency, this research has assessed the effect of merger on market proficiency. Thus, this study proposes to empirically examine the market efficiency for PSX, based on the premise that PSX was recently established on 11 Jan 2016, by merging the country's three former stock exchanges i.e., Karachi stock exchange, Lahore stock exchange and Islamabad stock exchange. The study uses event methodology and based its analysis in 90 day event of pre and post-merger daily accumulated abnormal returns of the market. Furthermore, our event study structure will consist of estimation window for estimating the expected return (Holler,2014) and event window for calculating the pre-post-merger accumulated abnormal returns for statistical comparison to determine the merger effect on the market efficiency (Neuhierl, Scherbina\&Schlusche,2011).

\subsection{Problem Statement}

Recently, the Pakistani stock exchanges had merged to form a single large security market, so does this formation has affected the market efficiency of Pakistani stock markets or not? For this reason, the study is carried out to find the impact of the event on the market information's efficiency.

\subsection{Objectives of the Study}

Producing event study matrix for observing the merger effect on the Market information's efficiency. Informing the national and international investors about the Pakistan stock exchange efficiency level after the merge. Consequently, providing results to the Government for their merger award, of integrating the three stock exchanges, both on stock market performance and market efficiency level, serving as 
information document for bringing reforms in regulations. Rationally, supplying the firms a picture of the market efficiency pattern, with a purpose that these firms briskly plan for future informational efficiency, by knowing the future money channel of securities dependent on securities prices.

\subsection{Research Question}

Does the market efficiency is affected by the stock exchange mergers in Pakistan?

\subsection{Significance of the Study}

The relationship consequences are very important for all the stock market Stakeholders. Established market efficiency level cause efficient portfolio management. Indeed, its importance is absorbed by the regulators as one of the important stakeholder. Obviously, the Government had issued the ordinance of merger of the three stock exchanges and these findings will provide consequences of the award to the Government, both on stock market performance and market efficiency. Certainly, this informational document will aware the market about current market efficiency trend; will enable the market to strategize actively for the future market efficiency levels maintenance, as stock based finance channel is dependent on stock prices. Fortunately, all the investors, whether individual or institutional can make efficient and effective portfolios of securities.

\subsection{Limitation of the Study}

The contemporary statistics investigation is only pertinent to existing environment because we have present indexes data. Rationally, we cannot anticipate the upcoming market efficiency through the following document because the future markets' efficiency is itself reliant on many forthcoming factors. Finally, this research does not qualify the Pakistan Stock Exchange as Weakly efficient market, SemiStrongly efficient market and Strongly efficient market but only show that the merger has improved the market information's efficiency.

\section{Literature Review}

Finance Scholars were incognizant about the indispensable idea of random walk till 1950s, when a brilliant statistician; Maurice Kindle, in 1953 had observed the randomness in the stock returns data of longer horizon and concluded that "the stock returns follow a random walk". He called this concept as "Random Walk Hypothesis". After the door was unlocked, many outstanding researches were conducted for investigating the truthfulness of "Random Walk". The most distinguished effort had been made by Eugene Fama, in 1970, by acknowledging the validate of Random walk hypothesis, through proposing the new theory "Efficient Market Hypothesis". Per his theory, both the public or private market information pertinent to securities is available in time to all stock market stakeholders and is speedily reflected in the security prices. Furthermore, he had declared through his mathematical proof that the markets are efficient and follow the random walk model. The title of his famous theory was "Efficient Market Hypothesis", supporting the market random walk model.

Logically, he had classified the Efficient Market Hypothesis into three classes:(a) Weak Efficiency form tests, (b) Semi-Strong efficiency form tests and (c) Strong efficiency form tests. Therefore, he had approved various statistical tests for ratifying an established efficiency level to the target market. Furthermore, he had collected the empirical evidence from the U.S. stock markets and written the above thesis as his Ph.D. dissertation. 
On the other hand, Paul Samuelson, an intelligent scholar, pursingBachelier's works, had provided scientific proof for the verification of Efficient Market Hypothesis. Salman and Mustafa (2001) had assessed the collective marketplace movement and evluated the causative effects of market efficacy on excess yield. They had obtained the indexes' information from the security exchange and it was comprised of (a) dayto-day indexes' returns (b) abnormal selling volume. More, the statistical models used for testing in the research were, autocorrelation test, midding methodology, logarithms and regression. The thesis outcomes had supported the Efficient Market Hypothesis and mathematical reinforced the notion thatthe market statisticsdoes immensely effect share prices. So, security prices rapidly adapt to all the available marketplace data in efficient markets and deferred in inefficient markets.

Brunnermeier (n.a) had investigated the relationship between the insider trading and marketplace proficiency. The analysis had revealed that management or agent holding the public or private information, surely obtain profits from the stock market for a short time. But in the long run, keeping the market statistics does not promise gains. Wayne E. Ferson and Tie Su Andrea Heuson (2005) had studied the market effectiveness through the Bi-pronged strategy and fined that the times variation in gains is excellently exhibited by Semi-Strong market efficacy based applications. They had used the square data of security returns on monthly basis. Furthermore,they had also investigated the problem statement through the event window methodology, to check the level of the market proficiency.

This is an examination of the global nexus of the discreet stock markets, tackled by Kam C. Chan, Benton E. Gup and Ming-Shiun Pan (1992), in which they investigated the universal connectivity of renowned security markets; logically, they had studied their market efficacy in the integration state through the co-integration test, to find their market efficiency in the discreet as well as in grid state. Those mergers whose co-integration value reinforced, that the combined have the missintegrated share prices; were declared as well-organized fused markets, and for those union markets whose co-integrations figures supports, the stock prices integrated were declared as incompetent markets.

Fifielda and Jetty (2008) had examinedthe Chinese stock markets, more discreetly the A-Share market and the B-Share market, for assessing its market competency. Rationally, they had obtained the everyday statistics of 370 firms, applied the variance ratio test to investigate the causality in the marketplace data. The analyses' outcomes had evidenced that the A-Share marketplace is more systematically effective than the B-Share marketplace. Also, the strict Chinese market regulations had increase the market competency of both markets.

Datta, D'Mello and Datta (2009) had analyzed the effects of CEO salary on the marketplace competency. Their examination results had shown that if the CEO remuneration is equity based, so it will boost both the effectiveness of capital budgeting and market efficiency. oliton and Fractals (2009) were investigating the effects of Price-limit system on the market efficiency. They had extracted the statistics from China, Korea and Taiwan stock markets. Furthermore, the rolling bicorrelation test statistic was used to reveal the nature of bond. Finally, the study outcomes had confirmed mathematically that the Price-limit system and the marketplace efficacy had positive relationship.

Chung and Hrazdil (2010) had used CRS on a group of firms, which were selected and taken from the NYSE. The analytical findings had shown that the 
liquidity and market efficacy are moving in the same direction as the security trading and firm size. The next task of the investigation was to observe the behavior of security returns for examining its predictability potential, core test for deciding the target market competency in the weak form. The need of the analysis was to absolutely recognize the target marketplace. Ultimately, the study outcomes had concluded that the market liquidity and market efficiency are positively related.

Alan Harper and ZhenhuJin (2011) had tested the weak form of market efficiency for the Indian stock markets. They had obtained the day-to-day returns of various indices of Indian security markets for studying its anticipatable strength. Furthermore, the range of statistics was from 1997 to 2011 . They had used the statistical tests to analyze the stock returns behavior, central test for approving the weak form of market efficacy for the target marketplace. The statistical modules were Autocorrelation test, the Box-Ljung test and Run test. Consequently, the assessment results had confirmed that stock returns are non-random and significant gains can be made through both fundamental analysis and technical analysis. Therefore, by considering the above scientific proofs, we conclude that the security prices do not reflect all the required statistics. Therefore, these mathematical proofs had supported the fact that the Indian stock exchanges; are in proficient in the weak form.

Abdmoulah (2010) had investigated the market efficacy of Arab markets; he had taken the everyday stock returns statistics of Arab security markets with data extending over many years. For scientific evidence, he had used the GARCH-M(1,1) i.e. (Generalized Autoregressive Conditionally Heteroskedastic in Mean). The GARCH-M $(1,1)$ i.e. (Generalized Autoregressive Conditionally Heteroskedastic in Mean), results had concludedthat the markets are in proficient in the weak form and the then current crisis are circulating in the economy. Kühl (2010) had examined the Dollar-Euro exchange rates co-relation with other trading rates. For this purpose, vector error correction model (VECM) was applied with the rules set by Granger's Representation Theorem. Consequently, the unit root test was also used for testing exchange rates' linkage. The analyses' outcomes had shown positive connection between the exchange rates and concluded that the U.S.-Euro co-integration bond occur.

Lim and Kim (2011) had investigated the effects of the trade openness on the market proficiency. For this purpose, data of stock markets of longer horizon was obtained. Specifically, the variance ratio test and the panel regression were as statistical tools to unveil the relationship nature. Consequently, the findings had confirmed that the trade openness inject predictability pattern in the stock returns and thus reduce the market efficiency. Lin, Fei and Wang (2011), had studied the reforms in Shangia stock exchange through a rolling window method and local Hurst Exponent. The results of the analyses had concluded that overall the securities liquidity, market efficiency has increased; especially the large values of local Hurst exponent support the conclusion.

\section{Research Methodology}

\subsection{Matrix for Probing the Merger Impact on Market Efficiency}

For that reason, we had chosen the 100 index and All Share index, and extracted the regular price statistics, sideways of the pre-post-merger date i.e. 11 Jan 2016. Logically, initially we had calculated the everyday respective index returns and then the estimation window and event window is constructed. In case of the event window, primarily the event date was identified and following observations: t-90 pre- 
event observations and t+90 post-event observations were taken for the event window; so logically containing 181 statistical points. Rationally, we should investigate the pre-post event observations qualitatively and quantitatively, to show the event effects on the target variable. The event study methodology applied in this work states, that the expected return value is the most crucial value for analysis; estimated from the estimation window. The estimation window shall consist of unbiased past (event window) observations fluctuating between 30 and 750(Holler, 2014) and standard models like Market Model, Fama-French three Factor Model, Fama-French Four Factor Model, Mean Adjusted Return Model etc., are applied on the estimation window to estimate the expected return value. Since, we are studying the indices, rationally, the Mean Adjusted Return Model is conforming with our analysis and we had used 210 regular indices returns observations past event windows; in order to estimate the expected returns (Cable \&Holland, 1999). analytically, a column of abnormal returns is created by deducting the expected return value from regular actual returns values. Furthermore, the column of accumulated abnormal returns is created by summing up individual abnormal returns down the course for each day. Consequently, pre-post-event sets of accumulated abnormal returns are examined through a Line-Graph and t-Test (Neuhierl, Scherbina \& Schlusche, 2011). The mechanism for the line-graph contains that the two sets of accumulated abnormal returns around the event date, are plotted against the time of the event window on the line-graph, with a purpose to observe the impact of the event. On the other hand, for the mathematical investigation, two hypotheses are assumed: (a) Null hypothesis as Ho where $\mathrm{u}=\mathrm{O}$, meant that there is no statistical significance (b) Alternate Hypothesis as $\mathrm{H} 1$ where $\mathrm{u} \neq \mathrm{O}$, meant that there is statistical significance. For this purpose, we had used the t-test and the t-values will speak about the data's statistical significance. A largenumerical value of t-test will reinforceH1 and ultimately Ho will be dropped and a small value of t-test will favor Ho acceptance and $\mathrm{H} 1$ will be discarded. Scientific decisions about the fate of hypotheses can also be carried out through P-Values. If the P-Value is $\leq \alpha$ so the Ho hypothesis is dropped and $\mathrm{H} 1$ is accepted and if the P-Value is $>\alpha$ so the probability of accepting Ho surges and the percentage of discardingH1 increases as well. systematically, we had constructed two event windows because we are having two indexes i.e. 100 index and All share index.

\subsection{Theoretical Framework}

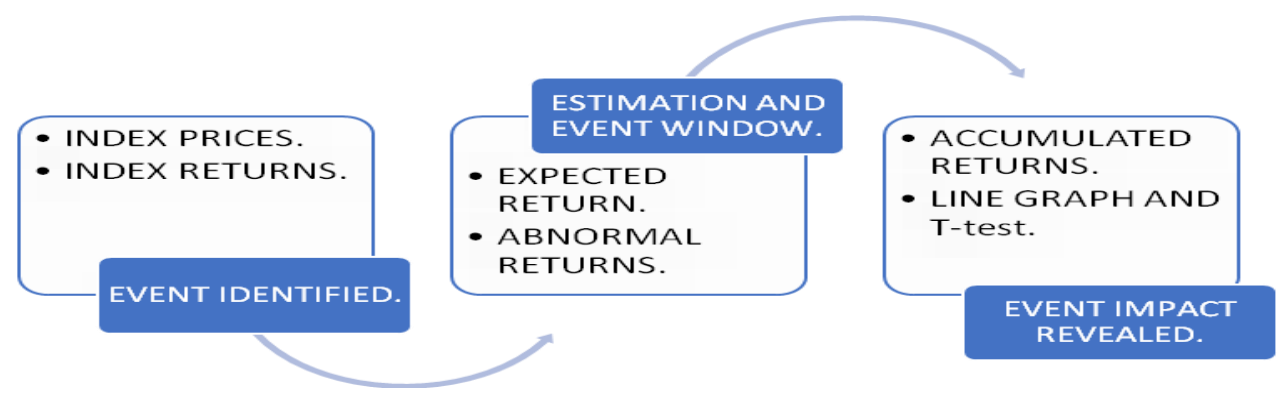




\section{Data Investigation and Outcomes}

\subsection{KSE-PSX 100 Index}

Primarily, we had generated the event window for the 100 index, by choosing the Ninety observations of KSE 100 index at pre-merge and Ninety observations of PSX 100 index at post-merge (11 JAN 2016). The examination of the event window is as follow:

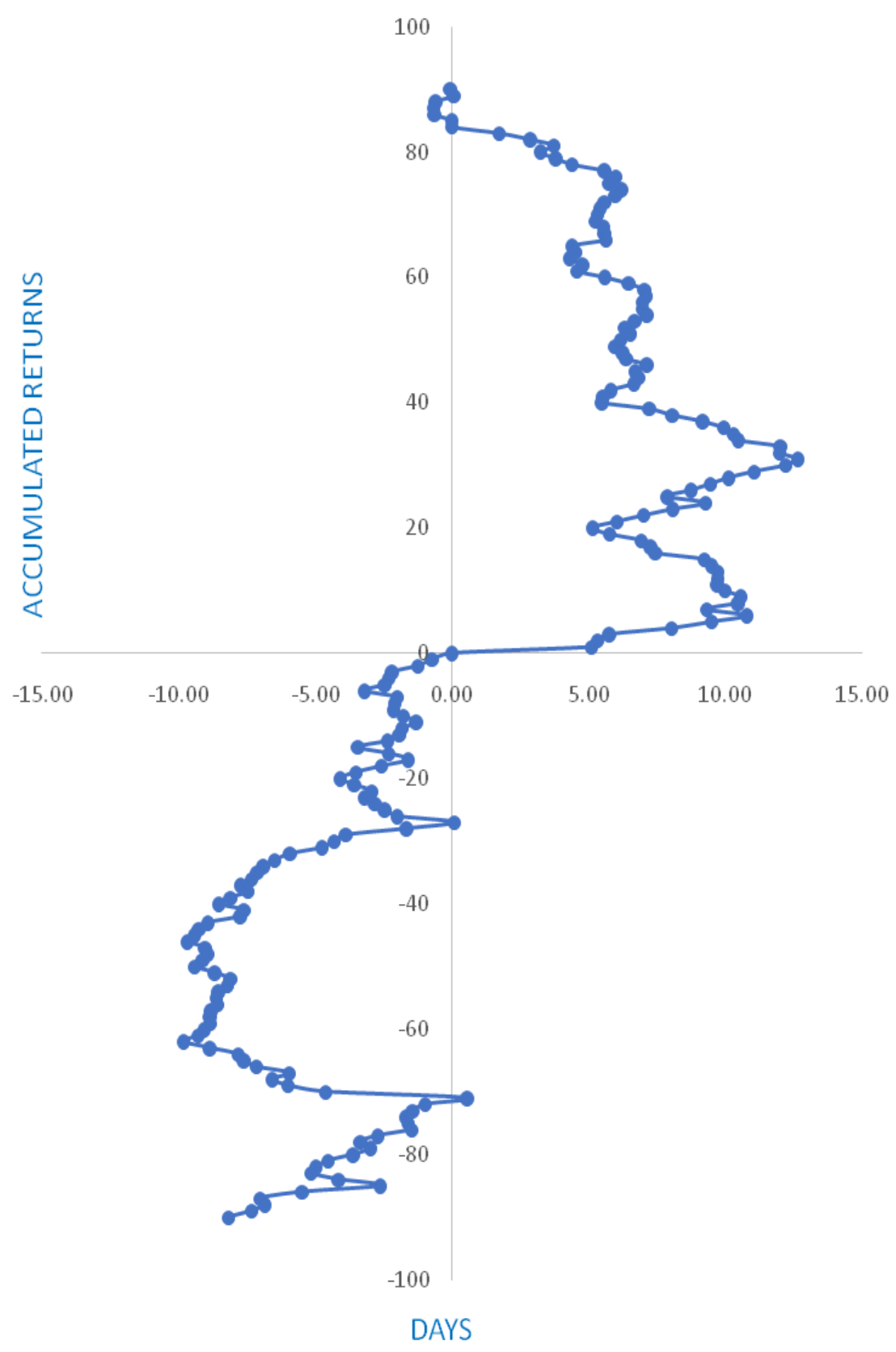


Table 4.1.a. t-TEST for 100 INDEX

\begin{tabular}{lll}
\hline \hline & PSX 100 & KSE 100 INDEX \\
& INDEX & \\
\hline \hline Mean & 6.566440972 & 5.182918137 \\
Variance & 9.023213481 & $\mathbf{8 . 8 7 5 2 1 6 8 2 4}$ \\
Observations & 90 & 90 \\
Pearson Correlation & -0.508147279 & \\
Hypothesized Mean Difference & 0 & \\
Df & 89 & \\
t Statistics & 21.45401519 & \\
P Value & $3.08801 \mathrm{E}-37$ & \\
\hline
\end{tabular}

The above investigation, in the table 4.1a, propagate that the two statistical sets i.e., PSX 100 Index and KSE 100 index, at the sideways of the event data are statistically significant. Because the t-Test statistic value is immensely substantial i.e. $21.451>2$, so on this base, the H1 hypothesis is accepted and Ho is spurned. The PValue is also immensely negligible i.e. $3.08801 \mathrm{E}-37<\alpha$, rationally it concludes that the difference is significant; thus, the Ho hypothesis is rejected and H1 is accepted. It concludes that the blend has surged up security market performance because the combined market effect has un-slumped the stock market efficiency. Furthermore, the investors are receiving the required marketplace statistics in time and earning the returns. Consequently, presently Pakistan Stock Market was lauded as the best stock market in South-Asia and was noticed globally for giving persistent increasing returns to the investors. The present Governments' ordinance on 11 Jan 2016 for blending the three stock exchanges i.e. Karachi Stock Exchange, Lahore Stock Exchange and Islamabad Stock Exchange, has brought increase in Market Efficiency and Stock Returns, as the above examination is the proof.

\subsection{KSE AND PSX All Share Index}

Now, the event window for the All share index is created by, i.e., by taking Ninety observations of KSE All share index at the pre-merge and Ninety observations of PSX All share index at the post-merge. The investigation and outcomes are as follow

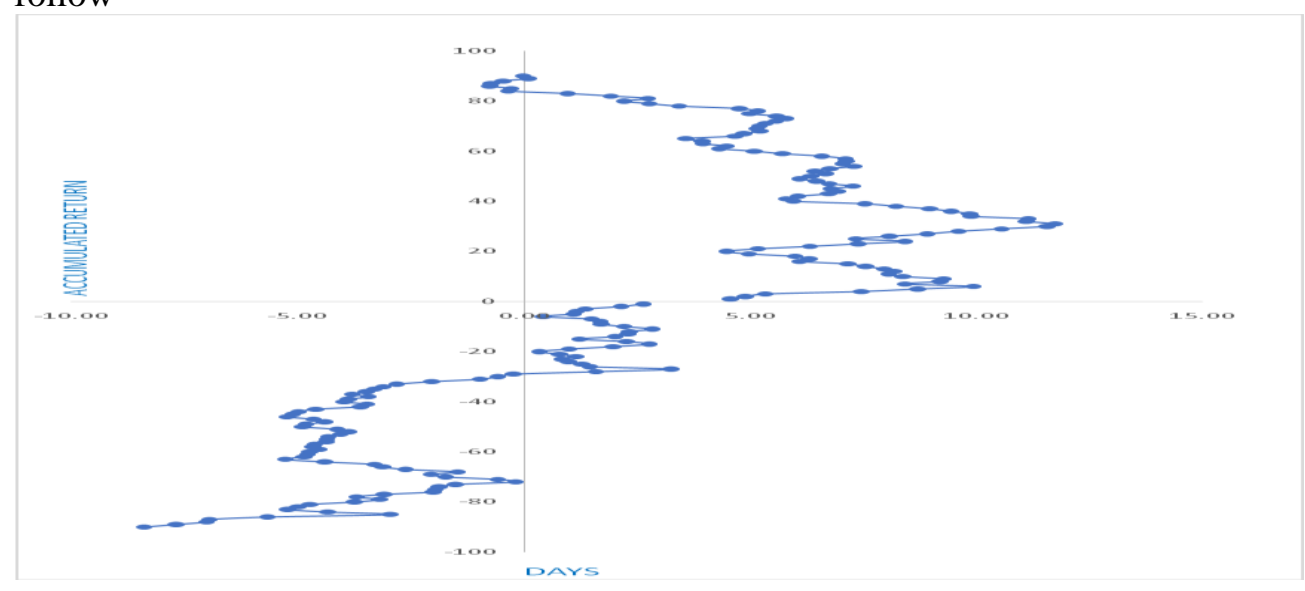


Table 4.2.b. t-test for All Share Index

\begin{tabular}{lll}
\hline \hline & $\begin{array}{l}\text { PSX All Share } \\
\text { Index }\end{array}$ & $\begin{array}{l}\text { KSE All Share } \\
\text { Index }\end{array}$ \\
\hline \hline Mean & $\mathbf{6 . 0 4 3 1 6 2 3 2 9}$ & $\mathbf{- 2 . 1 0 6 8 7 1 3 9 2}$ \\
Variance & $\mathbf{8 . 0 9 6 8 9 1 3 2 1}$ & $\mathbf{8 . 5 3 6 5 7 0 2 9 7}$ \\
Observations & 90 & 90 \\
Pearson Correlation & $-\mathbf{0 . 7 0 3 0 5 1 3 8}$ & \\
Hypothesized Mean & 0 & \\
Difference & & \\
Df & 89 & \\
t Stat & 14.52803208 & \\
P Value & $1.62652 \mathrm{E}-25$ & \\
\hline \hline
\end{tabular}

The above examination, in the table $4.2 \mathrm{~b}$ reveal that the difference in the two data sets is statistically significant. Because the t-Test statistic value is immensely substantial i.e. 14.52803208>2, so on this base $\mathrm{H} 1$ hypothesis is accepted and Ho is dropped. Logically, the P-Value is absolutely negligible i.e. $1.62652 \mathrm{E}-25<\alpha$, rationally it also concludes that the difference is significant; thus, the Ho hypothesis is repulsed and $\mathrm{H} 1$ is accepted. So, the study show that the fusion of markets has improved the stock market performance and the market efficiency. Obviously, the union has positively impacted the market efficiency and the market efficacy is continuously surging. In addition, the investors are getting the required market data in time and earning the profits. Subsequently, currently Pakistan Stock Market was commended as the finest stock market in South-Asia and was observed globally for giving tenacious surging returns to the investors. The present Government order on 11 Jan 2016 for fusing the three stock exchanges i.e. Karachi Stock Exchange, Lahore Stock Exchange and Islamabad Stock Exchange, has caused significant increase in Market Efficiency and Stock Returns, as the above investigation is the proof.

\section{Conclusion}

It has now been experientially proven that the fusion of markets had surged the marketplace efficacy.The union has positively impacted the market competency and the market proficiency is continuously growing. In addition, the investors are getting the required marketplace statistics in time and earning the profits. This is boosting the investors' morale to invest their funds. And if the present level of informational efficiency is maintained with principles of continuous improvement, so very soon a healthy investment culture will build up in Pakistan and it will expand. On the other side, the firms have high probability of obtaining substantial funds because of the investors' present attraction to the security markets and are in best position to manage the future marketplace information's efficacy level for upcoming cashflows. Furthermore, the Government aim of achieving 6-9\% GDP Growth is dependent on several factors and the security exchange boom performance, indeed, can significantly contribute on multi-sides. Consequently, the current Pakistan Stock Exchanges' boom performance has substantial contributed to the GDP Growth and the Government will pursue the objectives of maintaining the continuous improvement in the Market efficiency by further stringing its laws on Public, Private information disclosure. Vividly, Pakistani Security Markets are presently very well performing and are lauded as the finest security markets of South-Asia. Hap fully, it 
is included in the international list of security markets, as the best performing, security market of Asia; giving consistent increasing returns to the investors. Furthermore, local as well as international investors are coming back to the Pakistani Security Markets and very soon Pakistan Stock Exchange will be included in Emerging Markets. logically, the rise in the market efficacy had brought reliability in the Pakistani stock markets for thea investors over security trading.

\section{References}

Abdmoulah, W. (2010). Testing the evolving efficiency of Arab stock markets. International Review of Financial Analysis. Vol, (19), pp. 25-34. Online available on http//: www.sciencedirect.com.html. Retrieved on September 22nd, 2011.

Alan, H. \& Valparasio, Z. J. (2011). Examining market efficiency in India: An empirical analysis of the random walk hypothesis. Journal of Finance and Accountancy. http://www.aabri.com/copyright.html.

Ali, S. S. \&Mustafa, K. (2001). Testing Semi-Strong Form Efficiency of Stock Market. The Pakistan Development Review, 40:(4) Part II, pp. Retrieved on September 22nd, 2011

Benninga, S. (2008). Financial modeling (3 ed.). Boston, MA: MIT Press. https://www.eventstudytools.com/excel.

Brunnermeier, M. K. (2005). Information Leakage and Market Efficiency. The Review of Financial Studies. Vol. 18, No. (2), pp. (417-457). Online available on http//: www.jstor.org.html. Retrieved on September 22nd, 2011.

Cable, J. \& Holland, K. (1999). Modeling Normal Returns in Event Studies: A model-selection approach and pilot study. 5 (4): 331-341

Campbell, J. Lo, A.\& MacKinlay, A.C. (1997). The econometrics of financial markets.

Chordia, T., Roll, R. \& Subrahmanyam, A., (2008). Liquidity and market efficiency. Journal of Financial Economics 87, (249-268). Online available on http//: www.sciencedirect.com.html. Retrieved on September 22nd, 2011.

Datta, S., D’Mello, R. \& Datta,I. M. (2009). Executive compensation and internal capital market efficiency. J. Finan. Intermediation. Vol. 18, pp. (242-258). Online available on http/l: www.sciencedirect.com.html. Retrieved on September 22nd, 2011.

Dennis, C. \& Karel, H. (2010). Liquidity and market efficiency: A large sample study. Journal of Banking \& Finance. VOL, 34, pp. (2346-2357). Online available on http//: Nwww.sciencedirect.com.html. Retrieved on September 22nd, 2011.

Dimson, E. \&Mussavian, M. (1998). European Financial Management, Vol. 4, No. 1, pp. (91-193). Online available on http//: www.google.com.html. Retrieved on September 24th, 2011.

Fama, E. F. (1991). Efficient Capital Markets: I1. The journal of Finance. Vol. XLVI, No. 5, pp. (1575-1617). http//: www.google.com.html. Retrieved on September 24th, 2011.

Fama, E., (1991). Efficient Capital Markets:II.A review of theory and empirical work. Journal of Finance, VOL. XLVI, NO. $5 *$ DECEMBER 1991, p. (1576-1616). 
Ferson, W.E. \& Andrea, H. \& Tie, Su. (2005). Weak-Form and Semi-Strong-Form Stock Return Predictability Revisited. Management Science. Vol. 51, No. 10, pp. (1582-1592). Online available on http//: www.jstor.org.html. Retrieved on September 22nd, 2011.

Fifielda, S. G.M. \& Jetty, J. (2008). Further evidence on the efficiency of the Chinese stock markets: A note. Journal of Research in International Business and Finance. Vol. 22, pp. (351-361). www.sciencedirect.com. Retrieved on September 22nd, 2011.

Giaccotto, C. 7 Sfiridis, J.M. (1996). Hypothesis testing in event studies: The case of variance changes. 48 (4): 349-370.

Giaccotto, C. Sfiridis, J. M. (1996). Hypothesis testing in event studies: The case of variance changes. 48 (4): 349-370

Kam, C., Chan, B. Gup , E. \& Pan, S. S. Internationalstockmarketefficiencyand Integration:A study of eighteen nations.JournalofBusinessFinance \&Accounting, 24(6), July1997,0306-686X.

Kühl, M. (2010). Bivariate cointegration of major exchange rates, cross-market efficiency and the introduction of the Euro. Journal of Economics and Business. Vol. 62, pp. (1-19). Online available on http//: www.sciencedirect.com.html. Retrieved on September 22nd, 2011.

Neuhierl, A., Scherbina, A. \&Schlusche, B. (2011). 'Market reaction to corporate press releases'. Available at SSRN: http://ssrn.com/abstrac(1556532).https://www.eventstudytools.com/ex cel.

Ping, L. K. and Kim, J . H. (2011). Trade Openness and the Informational Efficiency of Emerging Stock Market. Economic Modelling. Vol. 28, pp. (2228-2238). Online available on http//: www.sciencedirect.com.html. Retrieved on September 22nd, 2011.

Ping, L.K. \& Brooks, R. D. (2009). Price limits and stock market efficiency: Evidence from rolling bicorrelation test statistic. Chaos, Solitons and Fractals. Vol.40, pp. (1271-1276). Online available on http//: www.sciencedirect.com.html. Retrieved on September 22nd, 2011.

Reilly, F. K., \& Brown, K. C. (2012). Investment Analysis and Portfolio Management $\left(10^{\text {th }}\right.$ edition $)$.

Sardar, I. M. N., Watanapalachaikul, S. \& Clark, C. (2005). Are Emerging Financial Markets Efficient? Some Evidence from the Models of the Thai Stock Market. Financial Modelling Program. Centre for Strategic Economic Studies. Victoria University, Melbourne, Australia. Online available on http//: www.google.com.html. Retrieved on September 24th, 2011.

Washburn, C. L. \& Clark, B. S. (1990). Informational Efficiency of Markets for Stumpage. American Journal of Agricultural Economics. Vol. 72, No.2, pp. (394-405). Online available on http//: www.jstor.comhtml. Retrieved on September 22nd, 2011. www.wikipedia.com. 2011. Retrieved on September 24th, 2011 www.people.stern.nyu.edu. 2011. Retrieved on September 24th, 2011.

Xiaoqiang, L., Fangyu, F. \& Wang, Y. (2011). Analysis of the efficiency of the Shanghai stock market: A volatility perspective. Physica A. Vol. 390, pp. (3486-3495). Online available on http/l: www.sciencedirect.com.html. Retrieved on September 22nd, 2011 